This is a self-archived - parallel published version of this article in the publication archive of the University of Vaasa. It might differ from the original.

\title{
Governance reforms, individualization of human resource management (HRM), and impact on workplace behavior - a black box?
}

Author(s): Demmke, Christoph

Title: Governance reforms, individualization of human resource management (HRM), and impact on workplace behavior - a black box?

Year: $\quad 2019$

Version: Accepted manuscript

Copyright (C)2019 American Society for Public Administration, published by Routledge, Taylor \& Francis Group. This is an Accepted Manuscript of an article published by Taylor \& Francis in Public integrity on 12 September 2019, available online: http://www.tandfonline.com/10.1080/10999922.2019.1656960.

\section{Please cite the original version:}

Demmke, C., (2019). Governance reforms, individualization of human resource management (HRM), and impact on workplace behavior - a black box? Public integrity. https://doi.org/10.1080/10999922.2019.1656960 


\section{Governance Reforms, Individualization of Human Resource management (HRM) and Impact on Workplace Behaviour - A Black Box?}

\section{Introduction}

The purpose in this paper is to discuss the relationship between destandardization trends in the field of Human Resource Management, ethical leadership, perceptions of organizational justice and workplace behaviour. We will argue that current destandardization, delegation and individualization trends in the field of HRM place additional burdens on line managers and HRM departments. In times of delegation of HRM responsibilities, managers are in the position to influence employee's careers, motivations, or even lives. Therefore, the way HRM is managed by line managers and individual agencies has ever stronger ethical implications and effects on organizational- and workplace behaviour.

The ultimate measure of any human resource (HR) system is the quality, efficiency, impartiality, professionalism and responsiveness that it delivers and how it furthers the possibilities to reach and fulfil objectives and helps deliver public services. As we will see, any HRM objective relates to ethics and any form of group behaviour, organizational culture, leadership, communication and HRM practice is related to organizational behaviour (Robbins/Jude/Campbell, 2017). On the other hand, ethical challenges abound in organizational- and human resource management (HRM) (Martin et al, 2017). Hence, HRM “is an inherently ethical activity in that its fundamental core is concerned with the treatment of humans; hence, conceptualizations of HRM automatically raise ethical considerations" (Greenberg, 2013, 355).

Strangely enough, the interest in the link between HRM and ethics has not kept pace with the growth of interest in other fields of ethics. Surprisingly, there is very little research on the link between HRM and ethics (Pinnington et al., 2007; Greenberg, 2013; Budd \& Scoville, 2005). For example, given the many initiatives in the field of managerial ethics, corporate social responsibility and company ethics, one might expect similar growth of interest in the field of civil service reform, HRM and ethics, too. "After all an extremely important component of making business more ethical is to take seriously the ethical aspects of managing people" 
(Pinnington et al., 207, 2). HRM managers and line managers make hiring decisions, assess competences, skills and performance, decide on training needs, rewards, sanctions, promotions, telework opportunities, diversity issues, dismissals, private-work balance, provide feedback, etc. However, attention to the ethical importance of decision-making in the main arenas of HRM tends to be minimal and sporadic. In fact, the ethical dimension HRM deserves more attention as an explicit ethical perspective and analysis. In our case, we will focus on one aspect of HRM reforms, the decentralization of HRM responsibilities to managers.

In the following, we will discuss the relationship between destandardization and delegation trends, ethical leadership, perceptions of organizational fairness and justice and workplace behaviour (Molina, Cropanzano \& Martinez-Tur, 2017). We define destandardization as a trend towards increasing variability and decreasing uniformity of HRM practices. We will argue that current destandardization, delegation and individualization trends in the field of HRM place additional burdens on managers. In times of de-bureaucratization, more job autonomy and flatter hierarchies, managers change, shape, direct and alter employees' lives. On the other hand, research has found that justice perceptions of the leader are strongly related to employee outcomes. Consequently, justice research has identified the leader as an important source of justice, individual and organizational outcomes (Karam et al., 2019). Therefore, not only the morality of HRM but also justice perceptions and outcomes are increasingly in the hands of managers and individual agencies, and more employees are vulnerable to opportunistic and unethical behaviour and individual discretionary and subjective behaviour of line managers and individual agencies. This throws more into question "the morality of contemporary HRM and increases the significance of engaging in moral evaluation of the behaviour of directors, managers and HRM practitioners" (Pinnington et al., 2007, 3).

Still, there is very little evidence on all these trends: In which HRM fields can we observe destandardization and delegation trends? What is individualization of HRM and how does this relate to ethics? How much discretionary power do managers have in taking HRM decisions? What forms of leadership behaviour impact on what type of organizational justice perceptions? How professional are managers in carrying out these tasks? Are managers aware of the importance of ethical leadership for different forms of justice perceptions? As we will see, academic discussions on all these trends are still very rudimentary. Thus, another purpose of this article is to suggest a new reform agenda in this field. 


\section{Individualization of HRM and Ethics}

Looking into the relationship of public management, HRM and ethics is a daunting task. Reforms in both public management and HRM have grown in complexity. This not only concerns the development of motivation theory but also leadership theories, the link between HRM and organizational performance and new evidence in the field of participation and voice. Overall, public management and HRM are not the preserve of legal and political science scholars anymore. Instead, these issues are dealt with in management science, organizational theory, behavioural economy, leadership theory, organizational justice, motivation theory, social cognitive theory, moral development theory, philosophy, organizational behaviour and law and identity politics (Fukuyama, 2018). Digitalization trends and budgetary pressures are also changing work systems by facilitating the management, monitoring, measuring and recording of individual efforts and engagement practices.

As a result, HRM is no longer treated as a purely technical issue that focuses on issues such as recruitment, selection, payroll, benefits, employee relations, performance management, industrial relations and legal issues. Instead, it has become an integral part of management, with an interest in all aspects of human life.

Overall, current trends in HRM have opened public employment to ever more diverse employment innovations. Whereas most governments agree that politics should not try to form the character or cultivate the virtue of its citizens, the increasing popularity of behavioural ethics, engagement policies and the growing importance of individual skill development, lifelong learning and intrinsic motivators show that current trends in HR policies are leading towards an individualization and 'psychologization' of HRM (Godard, 2014). For example, trends in the field of competency management place additional importance on the measurement of individual skill sets and the development of individual competences. Next, employees are required to be committed and engaged and develop organizational citizenship behaviour (OCB) in order to enhance their contribution to organizational performance (OECD, 2016a).

These developments run counter to a grand administrative tradition: For a long time, HRM in the public sector was dominated by rational, legal, standardized and technical approaches. Today, traditional public management and HRM doctrines are in trouble, both theoretically and practically, because they are challenged by ethical, financial and budgetary, behavioural and managerial narratives and developments in the neurosciences (Thompson, 
2011, 363). For example, writers like Dahlström and Lapuente have challenged the classical assumption that traditional HR features are effective in the fight against corruption, patronage and nepotism (Dahlström \& Lapuente, 2017).

Currently, the discipline of HRM integrates new evidence, especially from the behavioural sciences, and focuses on individuals. Consequently, the 'Bad Apple', “or focus on the person as a root cause, is making a reappearance" (Tenbrunsel \& Chugh, 2015, 207).

These trends are partly a reaction to the traditional focus in public administration reform, which was based on legal, economic and political ideas that ignored psychological aspects, although evidence existed since the Hawthorne Experiments (and even well before) that individual behaviour is influenced largely by intrinsic motivators, justice and fairness perceptions, emotions and feelings, such as hope, fear, aspirations, expectations, etc. Today, approaches that are based on laws and compliance-based approaches are believed to be ineffective since they guard only against intentional forms of unethical behaviour (and not unintentional forms). Consequently, behavioural ethics has become popular because these concepts offer psychological explanations about organizational and individual failure (and because people overestimate their ability to do what is right and why they (may) act unethically without meaning to (Bazerman \& Tenbrunsel, 2011)). This turn towards behavioural approaches can be explained partly on the basis of the shortcomings of traditional (bureaucratic) approaches. Another explanation is that discussions on behavioural ethics are apolitical. Everybody agrees on the explanatory power of this strand of research. An important side effect of this is that discussions on the relationship between the sociopolitical context, power relations and ethics have become less popular. Instead, we will claim that new behavioural approaches are only important and effective if they are embedded in the wider context of ethics policies, ethics management and ethics infrastructure. Individualized approaches to ethics only support a certain revision of rational thinking as such and a return to individualized approaches in public policy analysis.

\section{The Destandardization of HRM}

In the field of public management, the era in which obedience, hierarchical decision-making and treating all persons in the same way meant treating everybody fairly is not the paradigm of our times any more (Menzel, 2011).

The age of standardization and the decline of patronage government were well suited for the belief in and practice that equal treatment for all is fair treatment. However, postmodern 
societies along with ethnic, racial, gender, and age diversity have challenged elected officials and administrators around the world to rethink how to treat people unequally and yet to be fair. (Menzel, 2011, 122)

Consequently, diversity and identity politics have become popular. Therefore, a new challenge is to design fair HR systems under decentralized and individualized conditions that combine the efficiency and service capacity of decentralized organizations with the uniform and legalistic nature of hierarchical organizations (Peters \& Pierre, 2003, 6).

Decentralization, delegation and autonomy have been key features of HR reforms for decades. The belief, often drawn from the literature on management in the private sector, was that giving managers greater autonomy would lead to more effective accomplishment of the desired outcomes, to improvements in productivity and to a sharper focus on targets, employee performance and organizational performance (Coggburn, 2001, 2005).

It is therefore not surprising that reformers advocated a 'let managers manage' approach, the dominant assumption being that managers knew the right things to do.

Unfortunately, only few seemed to be interested in the assumption of what would happen if managers did not know what to do.

\section{Delegation and destandardization Trends in the Field of HRM}

Overall, in the field of HRM, destandardization, diversity and individualization reforms have been introduced in all OECD countries in a wide range of HR policies and HR structures. These concern the:

- destandardization and flexibilization of working time,

- destandardization and individualization in pay (through trends towards the differentiation of pay and performance-related pay [PRP]),

- destandardization of recruitment methods and procedures that were based on qualifications and not on skill development and competencies,

- destandardization and individualization of training, e.g. coaching and career development policies,

- destandardization and individualization of skill development and competency management policies, 
- flexibilization of retirement policies and retirement ages,

- flexibilization of contracts and employment policies,

- introduction of diversity policies,

- decentralization of HR competences to line managers,

- reform of the organization of work and provisions for more job autonomy,

- the possibility for more public-private, interministerial, intraministerial and intra-career mobility,

- the abolishment of traditional career progression policies such as automatic seniority progression.

All these developments create new opportunities, but also new challenges.

\section{Case: The Destandardization of Remuneration and Fairness Perceptions}

For a long time, civil servants in the same age cohort, with the same rank and the same qualification, were paid the same salary (which, often, was increased regularly in conformity with the principle of seniority and automatic pay progression). Traditional remuneration systems were established decades ago and for a long time they changed very little. The traditional focus on careers, stability, seniority and positions made sense when the vast majority in the public service had similar qualifications and jobs. The classical pay system was adapted to the dominant values at the time: bureaucratization, standardization and equality. Thus, whereas public pay systems were based on the principle of equality, private sector pay systems were based on that of autonomy. Today, the era in which treating everybody the same meant treating everybody fairly is not the paradigm of our times any more. Today, most people believe that everybody should be treated equally but also differently in order to be fair (Cooper, 2006, $53)$.

Consequently, traditional pay systems with their career ladders, time-based pay increases and specific allowances are increasingly reflecting a slowly disappearing concept of employment. That model was designed to reward loyalty by providing high levels of job security. Today, employees themselves expect immediate rewards and recognition for their individual accomplishments. So far, little research has been carried out on the impact of destandardization trends and the change of merit-based approaches on workplace behaviour and perceptions of organizational justice (among employees). Overall, pay diversity as such has increased within the national systems and among the different occupations and ranks (OECD, 
2017). Also, the structure of the systems has become more diverse. For example, today it is perceived as fair if civil servants earn higher salaries for demonstrating outstanding performance and receiving positive performance evaluations. However, one important question is whether and how professional and fair performance assessment are possible at all. This trend towards pay dispersion creates problems if managers fail to increase employees' perception of legitimacy of pay dispersion (and organizational fairness perceptions), which suggests that procedural fairness of the HRM systems can maximize the effectiveness of distribution of organizational resources, such as pay.

Public employees constantly compare their performance with that of their colleagues (Note: and mostly believe that they are better than others). Often, employees believe that their pay is not fair since they perform better than their colleagues. Many also believe that their performance is not managed, assessed and measured in a professional way. Consequently, fairness perceptions have changed and differ from the past. Currently, new feelings of being treated unfairly (for example by those who measure performance levels) emerge and, in many instances, people are even more demotivated and frustrated after the introduction of Performance Related Pay (PRP) (Denmmke, 2016). Since people constantly compare themselves with their colleagues, they also tend to believe that colleagues who receive bonuses and PRP do not deserve them. Often, employees who do not receive PRP may also be demotivated since they expected to get bonuses, etc. Another dilemma concerns the fact that many employees do not trust their superiors to take fair decisions on the allocation of PRP. Consequently, many people feel that they are treated unfairly because of unprofessional or unfair pay decisions of their superiors. In all these cases, the expectation to be treated individually conflicts with the expectation to be treated equally. As it seems, the individualization of pay and the growing differences in pay also produce higher levels of perceptions of distributional injustice.

Next, public administrations continue to align and fine-tune recruitment methods to specific skills needed (OECD, 2017, 76). Increasingly, this is being done by the introduction of more diverse and external recruitment practices, or separate practices, for exp. for top officials. Moreover, different public administrations increasingly design specific competency profiles for different categories of employees. However, this trend towards different competency expectations, skill development ability and self-reliance on skill adaptation marks a clear departure from the traditional view of the compliant bureaucrat (OECD, 2017, 61) and standardized recruitment policies. Today, countries wish to develop employment policies and 
recruitment frameworks that are driven by individual qualities, skills and expertise (OECD, $2017,10)$ in order to match new skill requirements and competency developments. All these trends raise the question of how individual skills are designed, evaluated and assessed under decentralized and individualized conditions (OECD, 2017, 67). At least in some countries, destandardized recruitment systems are more vulnerable to integrity violations than standardized systems.

\section{Towards Delegation and Autonomy of HR Decision-Making by Managers?}

As regards our interest, the first key question concerns the extent to which competences and authority, especially in those areas where destandardization trends have been passed down to lower levels of management and line managers, have been developed and exist at all.

According to an early OECD study $(2004,4)$, the reform trends in the field of HRM have resulted in individualization as well as fragmentation:

While in most countries, civil service rules applying to all civil servants used to be detailed and left little room for manoeuvre to manage staff individually, this situation has changed in all countries, even drastically in some.

The OECD study observed a significant trend towards individualising civil service arrangements. The results show that the trends towards individualisation have mostly taken place around the selection process, the term of appointments, termination of employment and performance management and pay. Strategies of staff management have become more individualised and staff can increasingly, in principle, be treated differently according to the changing needs of organisations and depending on their performance.

The OECD also warns that while the individualisation of HR practices is at the heart of the reforms aiming at increasing the responsiveness of the public service, it can have deleterious effects on collective values and ethical behaviour. (OECD, 2004)

Another study (Demmke, Hammerschmid, \& Meyer, 2007a) concluded that there is a lack of evidence and comparative information in regard to these central directions of current public administration modernization, especially about how decentralization affects leadership capabilities, working conditions of managers and the professional skills needed in HRM as well as issues of fairness and equity. However, an increasing number of countries are pursuing strategies to give senior and line managers greater responsibility and discretion (especially concerning budgetary questions, performance management and recruitment issues). Overall, it seems, (senior) managers have indeed received more (strategic, financial and budgetary) responsibility and discretionary powers in recent years. 
However, negative consequences of decentralization on equity and fairness issues are more relevant in cases where managers have been given discretionary powers to take important HR decisions on their own (especially decisions on pay, recruitment, training, promotion and/or evaluation and appraisal of staff). It is only in these cases that we can talk about a real individualization process. Meyer and Hammerschmid (2010) conclude in their analysis that managers are indeed given more responsibilities, but this does not mean that this process can be described as an individualization process. In most cases, managers do not have full discretion and decision-making powers and have to consult or coordinate their decisions with other, mostly hierarchically superior levels. Mostly, line managers have responsibilities in the field of performance management, PRP, career development and training issues, as well as disciplinary and dismissal issues.

Overall, delegation trends differ from country to country. Discretionary powers in HR matters are an exception, and many HR issues are a shared responsibility of many different parts of the administration. Generally, decision-making in the field of HR depends on civil service context, culture, HR system and is - to different degrees - participative. In most cases, HR experts, staff representatives, trade unions, HR central units, ministers and directors-general are more or less strongly involved (depending on the issue at stake).

Also, OECD survey data from 2016 (OECD, 2016b) confirms these trends. According to the survey, approximately two-thirds of all countries analysed $(n=39)$ are still of the opinion that, despite the introduction of many reforms, there still exists a broadly comparable framework for pay/terms and conditions of employment across all central, national and federal governments. Only in Finland, New Zealand, Sweden and Chile have reform trends resulted in a very diverse picture, with many different pay scales and terms and conditions of employment within each ministry or department. Another OECD (2017) study concludes that differences exist according to various HR policies: "However, delegation without some level of common HRM standards and central oversight often results in uneven pay scales, limits opportunities for government-wide strategic HR planning, and opens the door to nepotism and political interference in staffing decisions. Overall, there is no single model or common standard of delegation in HRM in OECD countries, and the variance in the extent of delegation across OECD countries is considerable. Whereas some countries like Slovakia and Sweden demonstrated a high degree of delegation, with the Slovak republic and Sweden standing out 
as the most prominent examples. In Sweden, delegation is accompanied by effective standards managed from the central HR authority and this enables more effective delegation. In comparison, Luxembourg and Israel display relatively lower levels of delegation, with central HRM bodies in these countries retaining greater responsibility over such decisions".

Almost all OECD countries (except for Germany and the Slovak republic) have at least one central HRM unit at central/national/federal levels (OECD, 2017).

Another study, by Bezes and Jeannot (2018), confirms the existence of a great diversity of systems. However, the authors also note that in some fields of HRM (autonomy in hiring, promoting or dismissing staff), line managers have considerable autonomy in taking HR decisions.

\section{Leadership Challenges and Organizational Justice - A Delicate Issue}

As we have seen, trends towards the individualization of decision-making and enhanced autonomy of line managers are still the exception in the field of HRM. In most cases, this concerns discretionary powers in the field of performance assessments and decisions in the field of PRP, career development and promotion, training, prolongment of contracts and - partly input in decisions on dismissal. Still, these decisions shed light on the great responsibilities of line managers. Each day, HR managers and leaders "change, shape, redirect, and fundamentally alter the course of other people's lives" (Margolis et al., 2012, 237). Failures and successes in carrying out these tasks have a notable impact on workplace behaviour, fairness perception, job engagement and performance. The role of the direct superiors in the assessment process provokes several important questions. In the course of a development towards more decentralized HRM responsibilities, the middle management level is increasingly entrusted with additional responsibilities, without always ensuring that this level can cope with and successfully 'manage' these tasks.

Because of these trends, ethical leadership is very important but also much more difficult, challenging and complicated as never before. Various factors such as a high daily workload, lack of training and information and deficient management skills and knowledge in setting and revising annual targets as well as assessing performance may be a real obstacle to successfully implementing performance assessments in administrative practice. Often, managers may lack incentives, skills and the necessary competences to better cope with these challenges. 
An empirical study by Demmke, Hammerschmid and Meyer (2007b) showed that managers themselves point to the following aspects as main (personal) challenges in the field of performance management:

- Aligning performance appraisal systems with other HR management processes, including career development and succession planning;

- Aligning individual performance objectives with organizational objectives/plans;

- Providing managers with the necessary competencies and training to effectively handle such assessment systems and to give feedback and coaching to their employees;

- Guaranteeing fairness and consistency in the practical application over time and between various organizational units;

- Clarifying and communicating objectives/targets and assessment criteria to staff; aligning performance ratings/scores and rewards/sanctions (Demmke \& Hammerschmid, 2007b).

Therefore, another question arises, namely whether too much is being expected of superiors. Are expectations to measure individual as well as organizational performance and subsequently - take decisions which take into account ethical consequences realistic at all? Do line managers overestimate themselves? Or do employees perhaps expect too much from their superiors? On the one hand, they expect their superiors to devote themselves entirely to managing, measuring, supporting and supervising employees (performance) according to their individual requirements. Line managers are made responsible for carrying out a complex performance appraisal procedure involving evaluations, feedback, target enhancements, developments, education plans, decisions on salary increases, promotions, dismissal contract prolongment and other functions at the same time, and this overload is becoming more and more unrealistic (Demmke, Hammerschmid, \& Meyer, 2008).

A simple and general answer to these challenges seems difficult at the very least: There is indeed a dilemma in all public services that require superiors to increasingly take important HR decisions with high ethical implications. On the other hand, most experts agree that professional management and ethical leadership are among the most essential tasks of managers' responsibilities. Consequently, they should be considered to be not additional, problematic tasks but core competencies of successful people management. However, this does not resolve the question of how employees perceive the justice and fairness of managers' decisions, and no comparative study has ever been carried out on these issues. Thus, the link between delegation of HR responsibilities and organizational justice is almost a 'black box'. 
Thus, while evidence is indeed mounting that ethics is strongly related to public management reforms, significant methodological and theoretical challenges still exist, especially in regard to the link between HRM and ethics. Consequently, research is still relatively silent in this field, although it is badly needed. Methodologically, there is no consensus regarding the various HR policies, HR strategies, policies and mechanism impact on ethical outcomes. Whereas sound empirical knowledge exists in regard to the positive link between meritocratic structures and levels of corruption and politicization, too little evidence exists in regard to the decentralization and delegation of HR competences and the impact on ethical leadership and organizational justice and fairness perceptions. Therefore, more empirical studies and more non-ideological deliberations in the field of HRM ethics are badly needed if we are to better understand ethical promises, challenges and limitations. One of these challenges is to understand how Government and HR policies are changing and how this impacts on ethics and workplace behaviour. In a study by Demmke and Moilanen (2012), officials from central administrations of all EU member states were asked whether reform policies that were introduced as a reaction to the financial crisis have had effects on workplace behaviour, such as decrease of trust in leadership, less job commitment, lower job satisfaction, anger, etc. In response, Hoekstra reported negative effects of austerity measures on the Dutch integrity system (Hoekstra, 2016). Also, the results of the Demmke and Moilanen study showed a strong relationship between the introduction of austerity measures and workplace behaviour. Apparently, employees are increasingly attentive to the justice of events across a variety of contexts. Increasingly, individuals react to actions and decisions made by organizations every day. Consequently, perceptions of unjust and unfair treatment can strongly influence individual behaviour and may have an important impact on individual and organizational behaviour and organizational performance.

Another study (OECD, 2016a) confirmed these findings. Thus, as Leo Huberts stated in 'The Integrity of Governance' $(2014,199)$, it is time for an 'integrity turn' in governance studies. However, it is also important "to relate the significance of our topics to power and power politics, to organization and management logics, and to other logics and rationalities of governance" (Huberts, 2014, 200).

\section{References}

Bazerman, M.H. \& Tenbrunsel, A.E. (2011). Blind Spots, Princeton, NJ: Princeton University Press. 
Bezes, Philippe \& Jeannot, Gilles (2018). Autonomy and managerial reforms in Europe: Let or make public managers manage? Public Administration, 96, pp. 3-22.

Budd, J.W. \& Scoville, J.G. (2005). The Ethics of Human Resources and Industrial Relations, Champaign: ILR Press.

Coggburn, J.D. (2001). Personnel deregulation: Exploring differences in the American States, Journal of Public Administration Research and Theory, 11, 2, pp. 223-244.

Coggburn, J.D. (2005). The benefits of human resource centralization: Insights from a survey of human resource directors in a decentralized state. Public Administration Review, 65, 4, pp. 424-435.

Cooper, T.L. (2006). The Responsible Administrator: An Approach to Ethics for the Administrative Role, 5th edition, San Francisco, CA: Jossey-Bass.

Dahlström, C. \& Lapuente, V. (2017). Organizing Leviathan, Cambridge: Cambridge University Press.

Dahlström, C., Lapuente, V. \& Teorell, J. (2012). The merit of meritocratization: Politics, bureaucracy, and the institutional deterrents of corruption. Political Research Quarterly, 65, 3.

Demmke, C (2016), Doing better with less?, The Future of the Government Workforce: Politics of Public HRM Reforms in 32 Countries,Frankfurt/M. et al: Peter Lang

Demmke, C., Hammerschmid, G. \& Meyer, R. (2007a). Decentralization and Accountability as Focus of Public Administration Modernisation. Challenges and Consequences for Human Resource Management, Maastricht: EIPA.

Demmke, C., Hammerschmid, G. \& Meyer, R. (2007b). The impact of individual assessments on organisational performance in the public services of EU member states, survey commissioned by the Portuguese EU-Presidency. Vienna and Maastricht, December 2007.

Demmke, C., Moilanen, T. (2012), Effectiveness of Public Service Ethics and Good Governance in the Central Admnistrations of the Eu Member States, Frankfurt/M. et al: Peter Lang

Fukuyama, F. (2018). Identity, London: Profile Books.

Godard, J. (2014). The psychologization of employment relations? Human Resource Management Journal, 24, pp. 1-18.

Greenwood, M. (2013). Ethical analysis of HRM: A review and research agenda. Journal of Business Ethics, 114, pp. 355-366. 
Hoekstra, A. (2016). Institutionalizing integrity management: Challenges and solutions in times of financial crises and austerity measures. Research Gate, DOI: 10.4324/9781315856865-9

Huberts, L. (2014). The Integrity of Governance: What It Is, What We Know, What Is Done, and Where To Go, Basingstoke: Palgrave Macmillan.

Karam, E.P., Hu., J., Dawson, R.B., et al. (2019). Illuminating the "face" of justice: A meta analytic examination of leadership and organizational justice. Journal of Management Studies, 56, 1, January 2019, pp. 135-171.

Margolis, J. Grant, \& Molinsky, A. (2007), Expanding Ethical Standards of HRM: Necessary Evils and the Multiple Dimensions of Impact. In Pinnington, A. Macklin, R. \& Campbell, T. (Eds.), (2007), Human Resource Management: Ethics and Employment, New York: Oxford University Press, pp. 237-251.

Martin, A. et al. (2017), Organizational Behaviour - Verhalten in Organisationen, $2^{\text {nd }}$ edition, Stuttgart: Kohlhammer

Menzel, D. (2011). Ethics and integrity in the public service. In: Donald Menzel and Harvey L. White (eds.) The State of Public Administration, London: Sharpe.

Meyer, R. \& Hammerschmid, G. (2010). Degree of decentralization and individual decisionmaking in central government human resource management: A European comparative perspective, In Public Administration, No. 2, June 2010, pp. 455-478.

Molina, C., Cropanzano, R. \& Martinez-Tur, V. (2017). Organizational Justice, New York: Routledge.

OECD (2004). Trends in Human Resources Management Policies in OECD Countries. An Analysis of the Results of the OECD Survey on Strategic Human Resources Management, Report of the Human Resources Management (HRM) Working Party, GOV/PGC/HRM (2004)3/FINAL, Paris: OECD.

OECD (2016a). Engaging Public Employees for a High Performing Civil Service, Paris: OECD.

OECD (2016b). Strategic HR Survey, Paris: OECD.

OECD (2017). Governance at a Glance, Paris: OECD.

Peters, G. \& Pierre, J. (Eds.) (2003). Handbook of Public Administration, Second edition. Thousand Oaks, CA: Sage Publisher. 
Pinnington, A., Macklin, R. \& Campbell, T. (2007). Introduction: Ethical human resource management. In: A. Pinnington, R. Macklin, and T. Campbell (eds.) Human Resource Management, Ethics and Employment, Oxford: Oxford University Press, pp. 1-23.

Robbins, S./Judge, T./Campbell, T., (2017), Organizational Behaviour, 2 ${ }^{\text {nd }}$ Edition, Harlow: Pearson

Tenbrunsel, T.A. \& Chugh, D. (2015). Behavioral ethics: A story of increased breadth and depth. Current Opinion in Psychology, September 2015, pp. 205-210, DOI: 10.1016/j.copsyc.2015.08.022

Thompson, P. (2011). The trouble with HRM. Human Resource Management Journal, 21, 4, pp. 355-367. 